\title{
Numerical Modeling on Radiative Dissipative MHD Flow of a Chemically Casson Fluid over an Exponentially Inclined Stretching Surface
}

\author{
Prathi Vijaya Kumar ${ }^{1}$, Shaik Mohammed Ibrahim ${ }^{1 *}$, Kanithi Jyothsna ${ }^{2}$ \\ ${ }^{1}$ Department of Mathematics, GITAM (Deemed to be University), Visakhapatnam, Andhra Pradesh 530045, India \\ ${ }^{2}$ Department of Basic Sciences and Humanities, Vignan's Institute of Engineering for Women, Andhra Pradesh 530049, India
}

Corresponding Author Email: shaikmohammed.ibrahim@gitam.edu

https://doi.org/10.18280/mmep.060403

Received: 2 October 2019

Accepted: 8 November 2019

\section{Keywords:}

Casson nanofluid, inclined stretching sheet, thermal radiation, viscous dissipation, HAM

\begin{abstract}
This article analyzes the magnetohydrodynamic Casson nanofluid flow over an exponentially inclined stretching permeable surface considering thermal radiation, suction/injection, heat source and chemical reaction in the flow region. Mathematical formulation is developed by assuming boundary layer approach. The leading differential equations are modelled by considering similarity transformations and solved using homotopy analysis method (HAM). Parametric behaviour of various physical constraints on velocity, temperature and concentration profiles is discussed through tables and graphs. Expressions of friction factor, rate of heat and mass transfer are evaluated graphically and also in tabular form for different values of parameters. The obtained results are in fabulous agreement with the existing results. Dual solutions are presented by considering suction and injection.
\end{abstract}

\section{INTRODUCTION}

Heat transfer has much utilization in several branches of engineering and science, e.g. reactor cooling, nuclear waste disposal, energy production, heat conduction in tissues, etc. Extensive studies on heat transmission in non-Newtonian fluids have been done by many investigators in previous centuries. Gupta and Gupta [1] first analysed the characteristics of heat transfer on a stretching sheet. Corell [2] studied the behavior of viscous fluid flow over a nonlinear stretching sheet. Shahzad et al. [3] obtained the exact solution of heat transfer flow along axisymmetric nonlinear radial stretching surface. Some relevant investigations on this subject can be found in the references [4-7].

Nanoparticles can be described as particles having size between 1-100nm. Nanoparticles are a field of dominant logical attention due to its broad variety of uses in utilization of energy, toluene, microelectronic, chemical production, floor heating, minerals etc. The terminology nanofluid was induced by Choi and Eastman [8]. Makinde and Aziz [9] discussed the behavior of nanofluid flow over a linear stretching sheet. Manusr and Ishak [10] studied the nature of a nanofluid flow past a stretching/shrinking sheet by considering convective boundary condition. Mabood et al. [11] derived the concept on MHD boundary layer flow of nanofluids over a nonlinear stretching sheet. Radiation effects on viscous nanofluid flow over a nonlinear stretching sheet were investigated by Hady et al. [12]. Nadeem et al. [13] and Mustafa et al. [14] were proposed a numerical solution of nonNewtonian nanofluid over a stretching sheet. Flow and heat transfer characteristics of nanofluid over a non-linear stretching sheet using similarity solutions was carried out by Hamad and Ferdows [15]. Chemical reaction and radiation effects on MHD mixed convection flow of a Casson nanofluid over a non-linear permeable stretching sheet was examined by
Jayarami Reddy et al. [16]. The influence of heat source and radiation on MHD stagnation point flow of Carreau nanofluid with suction and injection was analyzed by Jayarami Reddy et al. [17]. Suneetha et al. [18] reported the effects of Ohmic heating and thermal radiation on MHD mixed convective flow with various parameters.

Non-Newtonian fluids have made a notable attention due to its engineering and industrial applications. Examples of these fluids are paints, suspensions, emulsions, lubricants, and many biological fluids. The common features of all these daily used products are that they do not monitor Newton's law of viscosity. Therefore these fluids are labelled as nonNewtonian fluids. Thus, in order to study characteristics of these complex fluids, many fluid models have been suggested. These models are primarily categorized as time dependent fluids, viscoelastic fluids, time independent fluids. Out of these models, Casson fluid is one of time dependent fluid. Casson fluid model was proposed by Casson in 1959. Some samples of Casson fluid consist of honey, jelly, concentrated fruit juices and tomato sauce. Mustafa and Khan [19] discussed the magnetic field effect on Casson nanofluid over a nonlinearly stretching sheet. Ibrahim and Makinde [20] discussed the stagnation point flow of Casson nanofluid subject to slip and convective boundary conditions. Ibrahim [21] gave a numerical solution for the study of chemical reaction and heat source on MHD Casson nanofluid over a non-linear stretching sheet. The influence of chemical reaction and viscous dissipation on MHD mixed convection flow of Casson nanofluid over a nonlinear permeable stretching sheet was analyzed by Ibrahim et al. [22]. Mondal et al. [23] analyzed the convergence stability of MHD Casson nanofluid flow with Soret and Dufour effects. Using HAM Kumar et al. [24] studied the 3D radiative MHD Casson nanofluid over an exponentially porous stretching sheet under convective boundary conditions. 
In this paper, we study the characteristics of magnetohydrodynamic Casson nanofluid flow over an exponentially inclined stretching permeable surface using HAM. For more details on HAM, one may refer the literature done by the authors Kumar et al. [25], Hayat et al. [26], Liao [27] and Nadeem et al. [28].

\section{MATHEMATICAL FORMULATION}

We consider two dimensional flow of incompressible viscous electrically conducting magnetohydrodynamic Casson nanofluid over an exponentially inclined stretching surface.

- $\quad \alpha$ is an acute angle of inclination.

- The stretching velocity $U=U_{0} e^{x / L}$, temperature distribution $T_{w}=T_{\infty}+T_{0} e^{x / L}$ and concentration distribution $C_{w}=C_{\infty}+C_{0} e^{x / L}$.

- A variable magnetic field $B=B_{0} e^{x / 2 L}, B_{0}$ is a constant is applied along the normal direction to the motion of the sheet.

- We are considering radiation, viscous dissipation and heat soure in the flow region.

- The rheological equation of state for an isotropic and incompressible flow of Casson fluid is

$$
\tau_{i j}=\left[\begin{array}{ll}
2\left(\mu_{B}+\frac{p_{y}}{\sqrt{2 \pi}}\right) e_{i j}, & \pi>\pi_{c} \\
2\left(\mu_{B}+\frac{p_{y}}{\sqrt{2 \pi_{c}}}\right) e_{i j}, & \pi_{c}>\pi
\end{array}\right.
$$

where, $\mu_{B}$ is plastic dynamic viscosity of the non-Newtonian fluid, $p_{y}$ is the yield stress of the fluid, $\pi$ is the product of the component of deformation rate with itself, $\pi=e_{i j} e_{i j}, e_{i j}$ is the $(i, j)^{t h}$ component of the deformation rate and $\pi_{c}$ is a critical value of this product, based on the non-Newtonian model.

Under these assumptions the governing boundary layer equations are given by

$$
\begin{gathered}
\frac{\partial u}{\partial x}+\frac{\partial v}{\partial y}=0 \\
u \frac{\partial u}{\partial x}+v \frac{\partial u}{\partial y}=-\frac{1}{\rho} \frac{\partial p}{\partial x}+v\left(1+\frac{1}{\beta}\right)\left(\frac{\partial^{2} u}{\partial x^{2}}+\frac{\partial^{2} u}{\partial y^{2}}\right) \\
\pm g \beta_{T}\left(T-T_{\infty}\right) \cos \alpha+g \beta_{c}\left(C-C_{\infty}\right) \cos \alpha \\
-\frac{\sigma B_{0}^{2}}{\rho} u-\frac{v}{K^{*}} u \\
u \frac{\partial v}{\partial x}+v \frac{\partial v}{\partial y}=-\frac{1}{\rho} \frac{\partial p}{\partial y}+v\left(1+\frac{1}{\beta}\right)\left(\frac{\partial^{2} v}{\partial x^{2}}+\frac{\partial^{2} v}{\partial y^{2}}\right), \\
u \frac{\partial T}{\partial x}+v \frac{\partial T}{\partial y}=\frac{k}{\rho c_{p}} \frac{\partial^{2} T}{\partial y^{2}}+\tau\left[D_{B} \frac{\partial C}{\partial y} \frac{\partial T}{\partial y}+\frac{D_{T}}{T_{\infty}}\left(\frac{\partial T}{\partial y}\right)^{2}\right], \\
\left.\left.+\frac{1}{c_{p}}\left(1+\frac{1}{\beta}\right)\left(\frac{\partial u}{\partial y}\right)^{2}-\frac{1}{\left(\rho c_{p}\right.}\right) \frac{\partial q_{r}}{\partial y}+\frac{1}{\left(\rho c_{p}\right.}\right) Q_{0}\left(T-T_{\infty}\right)
\end{gathered}
$$

$$
u \frac{\partial C}{\partial x}+v \frac{\partial C}{\partial y}=D_{B} \frac{\partial^{2} C}{\partial y^{2}}+\frac{D_{T}}{T_{\infty}} \frac{\partial^{2} T}{\partial y^{2}}-\Gamma\left(C-C_{\infty}\right)
$$

Subject to the boundary conditions

$$
\begin{aligned}
& u=U+N \mu \frac{\partial u}{\partial \mathrm{y}}, v=-V(x), T=T_{w}+M \frac{\partial T}{\partial \mathrm{y}}, \\
& C=C_{w}+P \frac{\partial C}{\partial \mathrm{y}} \text { at } y=0, \\
& u \rightarrow 0, \quad T \rightarrow T_{\infty}, \quad C \rightarrow C_{\infty} \quad \text { as } y \rightarrow \infty .
\end{aligned}
$$

Here $N=N_{1} e^{-x / L}, M=M_{1} e^{-x / L}, P=P_{1} e^{-x / L}$. The no-slip can be attained by assuming $N=M=P=0$. It is assumed that $K^{*}=k_{1} e^{-x / L}, \Gamma=k_{0} e^{x / L}, \tau=\frac{(\rho c)_{p}}{(\rho c)_{f}}$ $q_{r}=-\frac{4 \sigma^{*}}{3 k^{*}} \frac{\partial T^{4}}{\partial y}=\frac{16 \sigma^{*} T_{\infty}^{3}}{3\left(\rho c_{p}\right) k^{*}} \frac{\partial^{2} T}{\partial y^{2}}$

Rosseland approximation),

Now, we introduce the following similarity transformations to convert the partial differential equations into ordinary differential equations:

$$
\left.\begin{array}{c}
\zeta=\left(\frac{U_{0}}{2 v L}\right)^{1 / 2} e^{x / 2 L} y, u=U_{0} e^{x / L} f^{\prime}(\zeta), \\
v=-\sqrt{\frac{\nu U_{0}}{2 L}} e^{x / 2 L}\left(f(\zeta)+\zeta f^{\prime}(\zeta)\right), \\
T=T_{\infty}+T_{0} e^{x / 2 L} \theta(\zeta), C=C_{\infty}+C_{0} e^{x / 2 L} \phi(\zeta)
\end{array}\right\}
$$

The pressure outside the boundary layer in quiescent part of flow is constant and the flow occurs only due to the stretching of the sheet and hence the pressure gradient can be neglected. Considering the usual boundary layer approximations, $u>>$ $v, \frac{\partial u}{\partial y}>>\frac{\partial u}{\partial x}, \frac{\partial v}{\partial x}, \frac{\partial v}{\partial y}$, the momentum equation in $y$-direction reduces to $\frac{\partial p}{\partial y}=0$. Now substituting Eq. (7) into the Eqns. (2) to $(6)$, we get

$$
\begin{aligned}
& \left(1+\frac{1}{\beta}\right) f^{\prime \prime \prime}+f f^{\prime \prime}-2 f^{\prime 2} \pm \lambda \theta \cos \alpha+\delta \phi \cos \alpha \\
& -(H+K) f^{\prime \prime}=0 \\
& \left(1+\frac{4}{3} R\right) \theta^{\prime \prime}+\operatorname{Pr}\left(\begin{array}{c}
f \theta^{\prime}-f^{\prime} \theta+N b \theta^{\prime} \phi^{\prime}+N t \theta^{\prime 2} \\
+\left(1+\frac{1}{\beta}\right) E c f^{\prime \prime 2}+Q \theta
\end{array}\right)=0, \\
& \phi^{\prime \prime}+S c\left(f \phi^{\prime}-f^{\prime} \phi\right)+\frac{N t}{N b} \theta^{\prime \prime}-S c \gamma \phi=0 .
\end{aligned}
$$

The boundary conditions are

$$
\begin{aligned}
& f(0)=S, f^{\prime}(0)=1+S_{v} f^{\prime \prime}(0), \quad \theta(0)=1+S_{t} \theta^{\prime}(0), \\
& \phi(0)=1+S_{c} \phi^{\prime}(0), \\
& f^{\prime}(\infty) \rightarrow 0, \quad \theta(\infty) \rightarrow 0, \quad \phi(\infty) \rightarrow 0,
\end{aligned}
$$


where, prime denotes differentiation with respect to $\zeta$, $H=\frac{2 \sigma B_{0}^{2} L}{\rho U_{0}}, K=\frac{2 v L}{K^{*} U_{0}}, G r=\frac{2 g \beta_{T}\left(T_{w}-T_{\infty}\right) L x^{2}}{v^{2}}$, $G c=\frac{2 g \beta_{C}\left(C_{w}-C_{\infty}\right) L x^{2}}{v^{2}}, \lambda=\frac{G r}{\operatorname{Re}_{x}^{2}}, \delta=\frac{G c}{\operatorname{Re}_{x}^{2}}, \operatorname{Pr}=\frac{v}{\alpha}$, $R=\frac{4 \sigma^{*} T_{\infty}^{3}}{k^{*} k} \quad, \quad N b=\frac{(\rho c)_{p} D_{B}\left(C_{w}-C_{\infty}\right)}{v(\rho c)_{f}}$ $N t=\frac{(\rho c)_{p} D_{T}\left(T_{w}-T_{\infty}\right)}{v(\rho c)_{f} T_{\infty}}, E c=\frac{U^{2}}{C_{p}\left(T_{w}-T_{\infty}\right)}, Q=\frac{Q_{0}}{\left(\rho c_{p}\right) U}$, $\gamma=\frac{2 L k_{0}}{U_{0}}, S c=\frac{v}{D_{B}}, S_{c}=P_{1} \sqrt{\frac{U_{0}}{2 v L}}, S_{t}=M_{1} \sqrt{\frac{U_{0}}{2 v L}}$, $S=\frac{V_{0}}{\sqrt{\left(\frac{U_{0 v}}{2 L}\right)}}$.

Non-dimensional skin friction coefficient $C_{f}$, local Nusselt number $N u_{x}$ and local Sherwood number $S h_{x}$ are

$$
\begin{gathered}
C_{f}=\frac{2 \tau_{w}}{\rho U_{0}^{2} e^{2 x / L}}, \text { where } \tau_{w}=\mu\left(1+\frac{1}{\beta}\right)\left(\frac{\partial u}{\partial y}\right)_{y=0}, \\
N u_{x}=\frac{x q_{w}}{k\left(T_{w}-T_{\infty}\right)} \text { and } S h_{x}=\frac{x J_{w}}{D_{B}\left(C_{w}-C_{\infty}\right)},
\end{gathered}
$$

where, $k$ is the thermal conductivity of the nanofluid, $q_{w}$ and $J_{w}$ are the heat and mass fluxes at the surface respectively given by

$$
q_{w}=\left(-\left(k+\frac{16 \sigma^{*} T_{\infty}^{3}}{3 k^{*}}\right)\left(\frac{\partial T}{\partial y}\right)\right)_{y=0}, J_{w}=-D_{B}\left(\frac{\partial C}{\partial y}\right)_{y=0} .
$$

Substituting $q_{w}$ and $q_{m}$ in the preceding equations, we get

$$
\begin{gathered}
R e_{x}^{1 / 2} C_{f} \sqrt{\frac{L}{x}}=\left(1+\frac{1}{\beta}\right) f^{\prime \prime}(0), \\
R e_{x}^{-1 / 2} N u_{x} \sqrt{\frac{L}{x}}=-\left(1+\frac{4}{3} R\right) \theta^{\prime}(0) \text { and } \\
R e_{x}^{-1 / 2} S h_{x} \sqrt{\frac{L}{x}}=-\phi^{\prime}(0),
\end{gathered}
$$

where, $R e_{x}=\frac{U_{o} x e^{x / L}}{v}$ is the local Reynolds number.

\section{HAM}

To grab the homotopic solutions of Eqns. (8) to (11), we pick up the initial guesses and linear operators as follows

$$
\begin{aligned}
& f_{0}(\xi)=S+\frac{\left(1-e^{-\xi}\right)}{\left(1+S_{v}\right)}, \\
& \theta_{0}(\xi)=\frac{e^{-\xi}}{\left(1+S_{t}\right)}, \\
& \phi_{0}(\xi)=\frac{e^{-\xi}}{\left(1+S_{c}\right)} . \\
& L_{1}(f)=f^{\prime \prime \prime}-f^{\prime}, \\
& L_{2}(\theta)=\theta^{\prime \prime}-\theta, \\
& L_{3}(\phi)=\phi^{\prime \prime}-\phi .
\end{aligned}
$$

with the following properties

$$
\begin{aligned}
& L_{1}\left(C_{1}+C_{2} e^{\xi}+C_{3} e^{-\xi}\right)=0, \\
& L_{2}\left(C_{4} e^{\xi}+C_{5} e^{-\xi}\right)=0, \\
& L_{3}\left(C_{6} e^{\xi}+C_{7} e^{-\xi}\right)=0,
\end{aligned}
$$

where, $C_{i}(i=1$ to 7$)$ are the arbitrary constants.

We construct the zeroth-order deformation equations

$$
\begin{aligned}
& (1-p) L_{1}\left(f(\zeta ; p)-f_{0}(\zeta)\right)= \\
& p \hbar_{1} N_{1}[f(\zeta ; p), \theta(\zeta ; p), \phi(\zeta ; p)], \\
& (1-p) L_{2}\left(\theta(\zeta ; p)-\theta_{0}(\zeta)\right)= \\
& p \hbar_{2} N_{2}[f(\zeta ; p), \theta(\zeta ; p), \phi(\zeta ; p)], \\
& (1-p) L_{3}\left(\phi(\zeta ; p)-\phi_{0}(\zeta)\right)= \\
& p \hbar_{3} N_{3}[f(\zeta ; p), \theta(\zeta ; p), \phi(\zeta ; p)],
\end{aligned}
$$

subject to the boundary conditions

$$
\left.\begin{array}{lr}
f(0 ; p)=S, \quad f^{\prime}(0 ; p)=1+S_{v} f^{\prime \prime}(0), & f^{\prime}(\infty ; p)=0, \\
\theta(0 ; p)=1+S_{t} \theta^{\prime}(0 ; p), & \theta(\infty ; p)=0, \\
\phi(0 ; p)=1+S_{c} \phi^{\prime}(0 ; p), & \phi(\infty ; p)=0 .
\end{array}\right\}
$$

$$
\begin{aligned}
& N_{1}[f(\zeta ; p), \theta(\zeta ; p), \varphi(\zeta, p)]=\left(1+\frac{1}{\beta}\right) f^{\prime \prime \prime}(\zeta ; p) \\
& +f(\zeta ; p) f^{\prime \prime}(\zeta ; p)-2\left(f^{\prime}(\zeta ; p)\right)^{2} \pm \lambda \theta(\zeta ; p) \cos \alpha \\
& +\delta \varphi \cos \alpha-(H+K) f^{\prime}(\zeta ; p), \\
& N_{2}[f(\zeta ; p), \theta(\zeta ; p), \phi(\zeta ; p)]=\left(1+\frac{4}{3} R\right) \frac{\partial^{2} \theta(\zeta ; p)}{\partial \zeta^{2}} \\
& +\operatorname{Pr}\left(f(\zeta ; p) \frac{\partial \theta(\zeta ; p)}{\partial \zeta}-\theta(\zeta ; p) \frac{\partial f(\zeta ; p)}{\partial \zeta}\right) \\
& +\operatorname{Pr}\left(\begin{array}{l}
\left.N b \frac{\partial \theta(\xi ; p)}{\partial \zeta} \frac{\partial \phi(\xi ; p)}{\partial \zeta}+N t\left(\frac{\partial \theta(\zeta ; p)}{\partial \zeta}\right)^{2}\right) \\
+\left(1+\frac{1}{\beta}\right) E c\left(\frac{\partial^{2} f(\zeta ; p)}{\partial \zeta^{2}}\right)^{2}+Q \theta(\zeta ; p)
\end{array}\right)
\end{aligned}
$$




$$
\begin{aligned}
& N_{3}[f(\zeta ; p), \theta(\zeta ; p), \varphi(\zeta ; p)]=\frac{\partial^{2} \varphi(\zeta ; p)}{\partial \zeta^{2}} \\
& +S c\left(f(\zeta ; p) \frac{\partial \varphi(\zeta ; p)}{\partial \zeta}-\varphi(\zeta ; p) \frac{\partial f(\zeta ; p)}{\partial \zeta}\right) \\
& +\left(\frac{N t}{N b}\right) \frac{\partial^{2} \theta(\zeta ; p)}{\partial \zeta^{2}}-S c \gamma \varphi(\zeta ; p),
\end{aligned}
$$

When $p=0$ and $p=1$, we obtain

$$
\begin{array}{ll}
f(\zeta ; 0)=f_{0}(\zeta) & f(\zeta ; 1)=f(\zeta), \\
\theta(\zeta ; 0)=\theta_{0}(\zeta) & \theta(\zeta ; 1)=\theta(\zeta), \\
\phi(\zeta ; 0)=\phi_{0}(\zeta) & \phi(\zeta ; 1)=\phi(\zeta) .
\end{array}
$$

Thus, as $p$ accelerates from 0 to 1 then $f(\zeta ; p), g \theta(\zeta ; p)$ and $\phi(\zeta ; p) \quad$ vary from initial approximations to the exact solutions of the original nonlinear differential equations.

Using Taylor's series, we get

$$
\begin{aligned}
& f(\zeta ; p)=f_{0}(\zeta)+\sum_{m=1}^{\infty} f_{m}(\zeta) p^{m}, \\
& \theta(\zeta ; p)=\theta_{0}(\zeta)+\sum_{m=1}^{\infty} \theta_{m}(\zeta) p^{m}, \\
& \phi(\zeta ; p)=\phi_{0}(\zeta)+\sum_{m=1}^{\infty} \phi_{m}(\zeta) p^{m},
\end{aligned}
$$

where,

$$
\begin{aligned}
& f_{m}(\zeta)=\left.\frac{1}{m !} \frac{\partial^{m} f(\zeta ; p)}{\partial p^{m}}\right|_{p=0}, \\
& \theta_{m}(\zeta)=\left.\frac{1}{m !} \frac{\partial^{m} \theta(\zeta ; p)}{\partial p^{m}}\right|_{p=0}, \\
& \phi_{m}(\zeta)=\left.\frac{1}{m !} \frac{\partial^{m} \phi(\zeta ; p)}{\partial p^{m}}\right|_{p=0}
\end{aligned}
$$

If the initial approximations, auxiliary linear operators and non-zero auxiliary parameters are chosen in such a way that the series (22) to (24) are convergent at $p=1$, then

$$
\begin{aligned}
& f(\eta)=f_{0}(\xi)+\sum_{m=1}^{\infty} f_{m}(\xi), \\
& \theta(\xi)=\theta_{0}(\xi)+\sum_{m=1}^{\infty} \theta_{m}(\xi), \\
& \phi(\xi)=\phi_{0}(\xi)+\sum_{m=1}^{\infty} \phi_{m}(\xi) .
\end{aligned}
$$

mth-order deformation equations are as follows

$$
\begin{aligned}
& L_{1}\left(f_{m}(\zeta)-\chi_{m} f_{m-1}(\zeta)\right)=\hbar_{1} R_{m}^{f}(\zeta) \\
& L_{2}\left(\theta_{m}(\zeta)-\chi_{m} \theta_{m-1}(\zeta)\right)=\hbar_{2} R_{m}^{\theta}(\zeta)
\end{aligned}
$$

$$
L_{3}\left(\phi_{m}(\zeta)-\chi_{m} \phi_{m-1}(\zeta)\right)=\hbar_{3} R_{m}^{\phi}(\zeta)
$$

with the following boundary conditions

$$
\begin{array}{lll}
f_{m}(0)=0, & f_{m}^{\prime}(0)=0, & f_{m}^{\prime}(\infty)=0, \\
\theta_{m}^{\prime}(0)=0, & \theta_{m}(\infty)=0, \\
\phi_{m}(0)=0, & \phi_{m}(\infty)=0,
\end{array}
$$

where,

$$
\begin{aligned}
& R_{m}^{f}(\zeta)=\left(1+\frac{1}{\beta}\right) f_{m-1}^{\prime \prime \prime}+\sum_{i=0}^{m-1} f_{m-1-i} f_{i}^{\prime \prime}-2 * \sum_{i=0}^{m-1} f_{m-1-i}^{\prime} f_{i}^{\prime} \\
& \pm \lambda \cos \alpha \theta_{m-1}+\delta \cos \alpha \phi_{m-1}-(H+K) f_{m-1}^{\prime}, \\
& R_{m}^{\theta}(\zeta)=\left(1+\frac{4 R}{3}\right) \theta_{m-1}^{\prime \prime}+\operatorname{Pr}\left(\sum_{i=0}^{m-1}\left(f_{m-1-i} \theta_{i}^{\prime}-f_{m-i-1}^{\prime} \theta_{i}\right)\right) \\
& +\operatorname{Pr}\left(N b \sum_{i=0}^{m-1} \theta_{m-1-i}^{\prime} \phi_{i}^{\prime}+N t \sum_{i=0}^{m-1} \theta_{m-1-i}^{\prime} \theta\right)_{i}^{\prime} \\
& +\operatorname{Pr}\left(\left(1+\frac{1}{\beta}\right) E c \sum_{i=0}^{m-1}\left(f_{m-1-i}^{\prime \prime} f_{i}^{\prime \prime}\right)+Q \theta_{m-1}\right) \\
& R_{m}^{\phi}(\zeta)=\phi_{m-1}^{\prime \prime}+S c\left(\sum_{i=0}^{m-1}\left(f_{m-1-i}\right) \phi_{i}^{\prime}-f_{m-1-i}^{\prime} \phi_{i}\right) \\
& +\left(\frac{N t}{N b}\right) \theta_{m-1}^{\prime \prime}-S c \gamma \phi_{m-1},
\end{aligned}
$$$$
\chi_{m}= \begin{cases}0, & m \leq 1 \\ 1, & m>1\end{cases}
$$

\section{CONVERGENCE OF HAM}

It is well recognized argument that HAM provides us great freedom and an informal technique to compute the convergence region of the series solutions. This convergence region mainly depends on the auxiliary parameter $\hbar$. To acquire the relevant values for these parameters, $\hbar$-curves are portrayed in Figure 1. From this diagrammatic representation, it is scrutinized that the plausible region of the parameters is about $[-1.0,0.0]$. For $\hbar_{1}=\hbar_{2}=-0.49$ and $\hbar_{3}=-0.65$, the series solutions are convergent in the whole region of $\zeta$. Table 1 displays the convergence of the method.

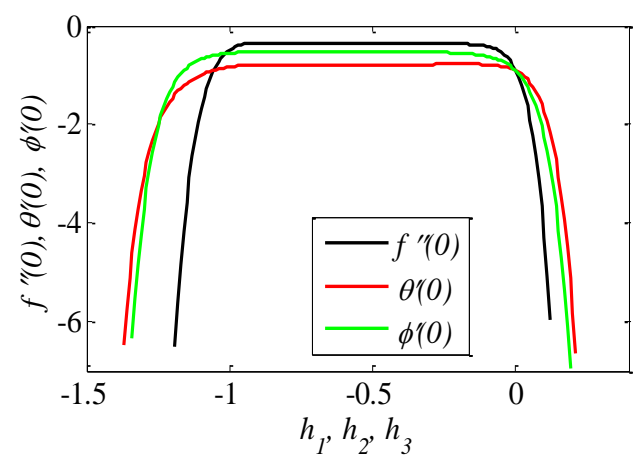

Figure 1. $\hbar$-curves for $f^{\prime \prime}(0), \theta^{\prime}(0)$ and $\phi^{\prime}(0)$ at $15^{\text {th }}$ order approximations 
Table 1. Convergence of HAM solution for different orders of approximations when $\beta=1.0, H=0.5, \lambda=\delta=2.0, K=$ $R=0.1, \operatorname{Pr}=0.72, N b=02, N t=0.2, E c=Q=0.1$, $S c=0.6, S_{v}=S_{t}=S_{c}=0.1, S=0.3, \alpha=\frac{\pi}{4}$.

\begin{tabular}{|c|c|c|c|}
\hline Order & $-f^{\prime \prime}(0)$ & $-\theta^{\prime}(0)$ & $-\phi^{\prime \prime}(0)$ \\
\hline 5 & 0.372066 & 0.782587 & 0.528452 \\
\hline 10 & 0.367840 & 0.785314 & 0.524781 \\
\hline 15 & 0.367549 & 0.785244 & 0.524270 \\
\hline 20 & 0.367619 & 0.785160 & 0.524339 \\
\hline 25 & 0.367656 & 0.785170 & 0.524339 \\
\hline 30 & 0.367657 & 0.785174 & 0.524339 \\
\hline 35 & 0.367657 & 0.785174 & 0.524339 \\
\hline 40 & 0.367657 & 0.785174 & 0.524339 \\
\hline
\end{tabular}

\section{RESULTS AND DISCUSSION}

In this, we panoply some results which bring acumen about the problem. For these computations, we consider the following values all over the study:

$$
\begin{aligned}
& \beta=1.0, H=0.5, \lambda=\delta=2.0, K=R=0.1, P r=0.72, N b=0.2, \\
& N t=0.2, E c=Q=0.1, S c=0.60, S_{v}=S_{t}=S_{c}=0.1, S=0.3, \\
& \alpha=\pi / 4 .
\end{aligned}
$$

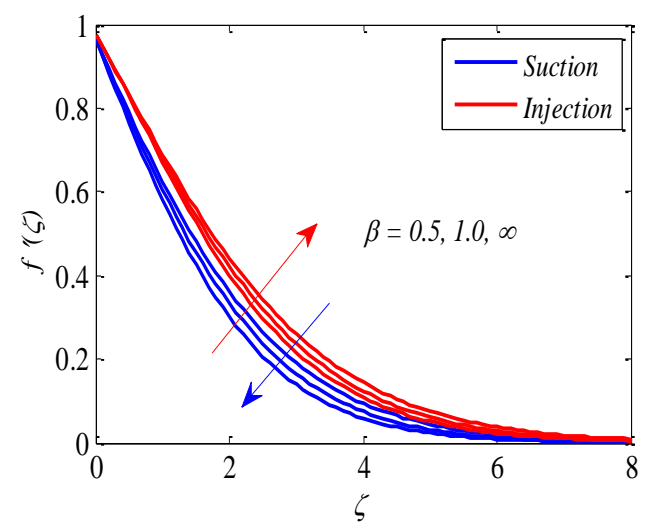

Figure 2. Effect of $\beta$ on $f^{\prime}(\zeta)$

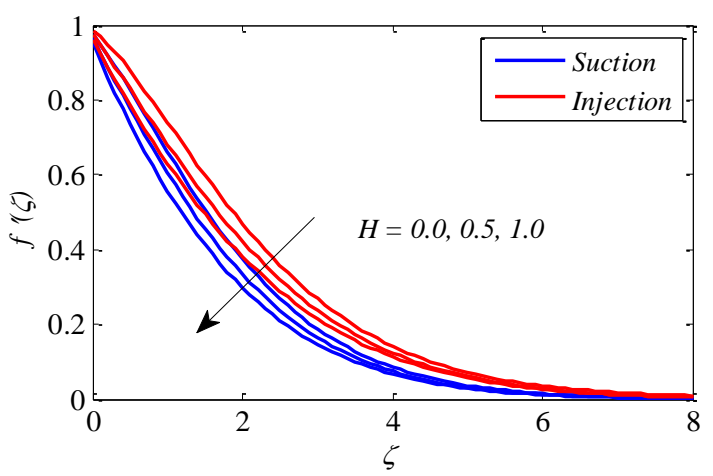

Figure 3. Effect of $H$ on $f^{\prime}(\zeta)$

Figure 2 is sketched to mention the repercussions of Casson parameter $\beta$ on velocity distribution $f^{\prime}(\zeta)$. It is elucidated that velocity drops with the increase of Casson parameter for suction $(S=0.3)$. This is because of plastic dynamic viscosity which reduces the fluid motion enhances with the Casson parameter. Opposite trend is observed for injection $(S=-0.3)$.
Larger values of magnetic parameter $H$ resemble an increase in Lorentz force which opposes the fluid motion. Hence velocity declines with magnetic parameter for both the cases. This reduction is more in suction then injection. This is shown in Figure 3. It is found that accelerating the porosity parameter $K$, devitalize the thickness of velocity field. This is because the holes of the porous layers expand with an increase in the porosity parameter and diminish the thickness of the momentum boundary layer. This is shown in Figuer 4.

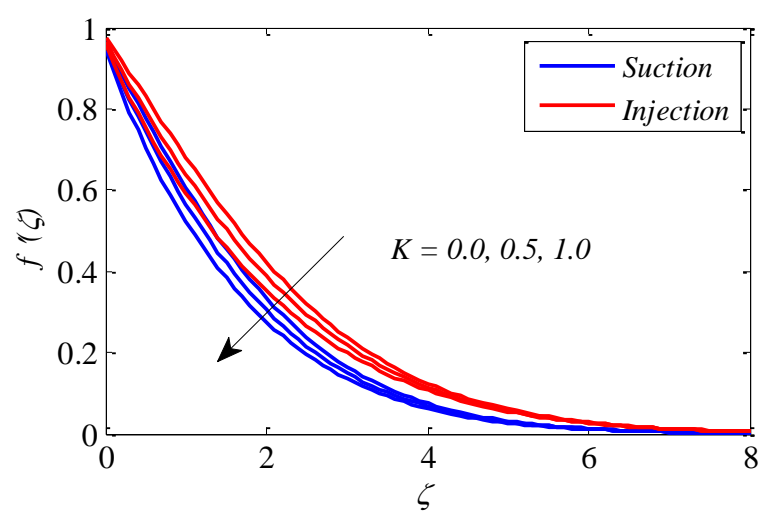

Figure 4. Effect of $K$ on $f^{\prime}(\zeta)$

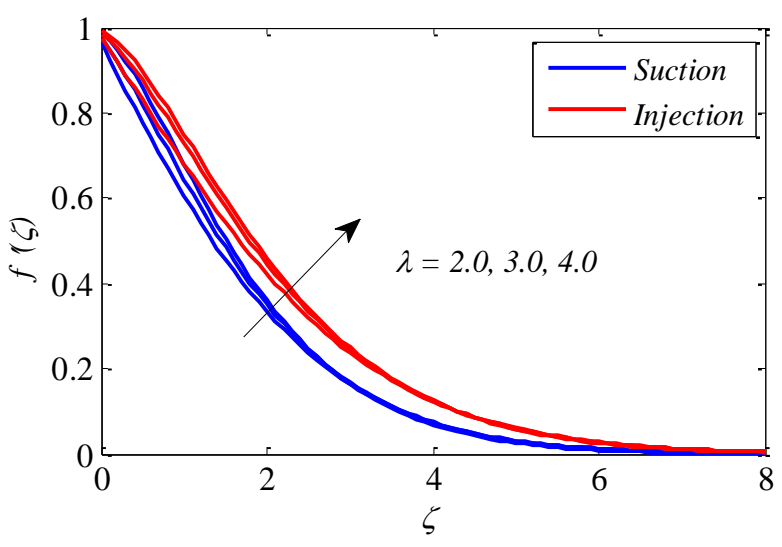

Figure 5. Effect of $\lambda$ on $f^{\prime}(\zeta)$

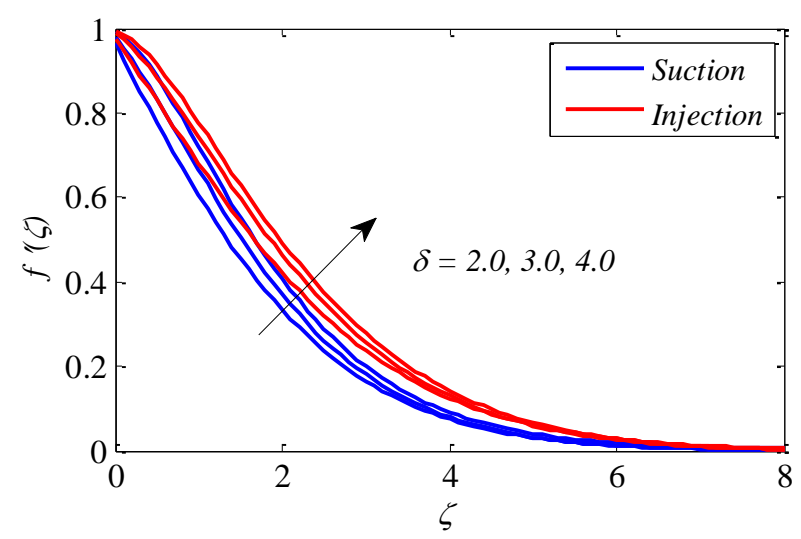

Figure 6. Effect of $\delta$ on $f^{\prime}(\zeta)$

Figures 5 and 6 demonstrate the impact of buoyancy parameter $\lambda$ and solutal buoyancy parameter $\delta$ on velocity. It is understood that velocity sketch upturns by enhancing the values of $\lambda$ and $\delta$. It is also noticed that this enhancement in the velocity filed is more on injection case compared with the suction case. The Angle of inclination $\alpha$ decreases the 
effect of the buoyancy force due to thermal diffusion by a factor of $\cos \alpha$. Hence velocity decreases with $\alpha$ for both the cases. This is shown in Figure 7. Effects of velocity slip $S_{v}$ on the velocity profiles are shown in Figure 8. It is observed that the velocity increases with $S_{v}$ up to certain value of $\zeta=1.8$ for both the cases. After that velocity increases slightly with $S_{v}$. Temperature profiles are displayed for various values of radiation parameter in Figure 9. It is observed that the radiation parameter $R$ uplifts the temperature distribution. This is because of the fact that the thermal boundary layer thickness improves with increasing radiation parameter for both the cases. It is also observed that accretion in the temperature field is considerably large in injection case. The deviation of Prandtl number $\mathrm{Pr}$ on temperature is explained in Figure 10. It is evident from figure that enhancing the values of Prandtl numbers $\operatorname{Pr}$ diminishes temperature profile. For lower Prandtl numbers refers to thermal diffusion and so momentum boundary layer structures thicker, therefore the heat can drawn-out from the sheet faster than advanced values of Prandtl number Pr. Figures 11 and 12 display the influence of thermophoresis parameter $N t$ and Brownian motion parameter $N b$ on temperature. It is clear that thermophoresis parameter $N t$ and Brownian motion parameter $N b$ boost up the temperature profiles. The repercussion of Eckert number $E c$ on temperature is initiated in Figure 13. It is observed that the temperature rises with the increase of $E c$.

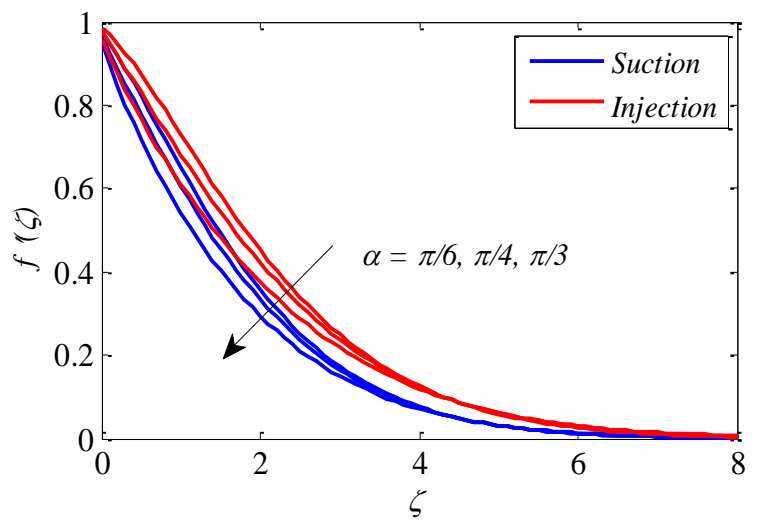

Figure 7. Effect of $\alpha$ on $f^{\prime}(\zeta)$

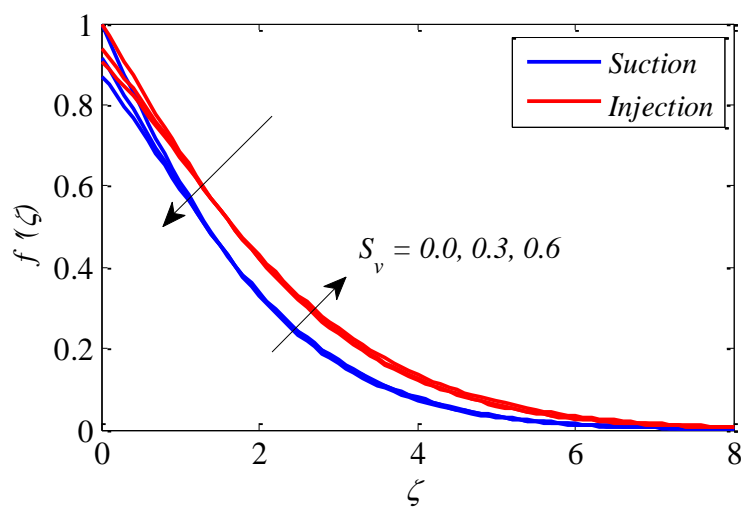

Figure 8. Effect of $S_{v}$ on $f^{\prime}(\zeta)$

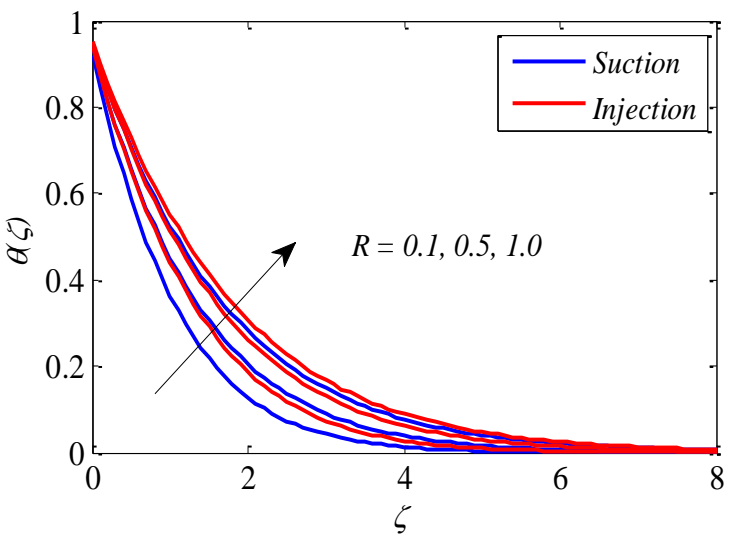

Figure 9. Effect of $R$ on $\theta(\zeta)$

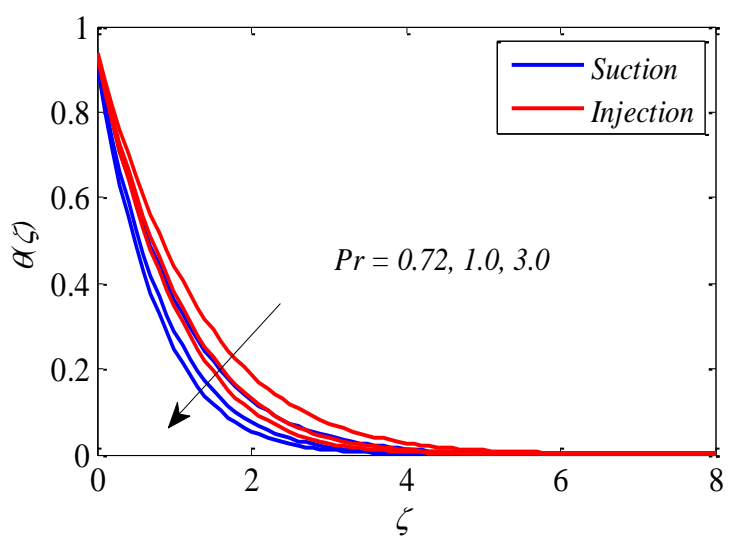

Figure 10. Effect of $\operatorname{Pr}$ on $\theta(\zeta)$

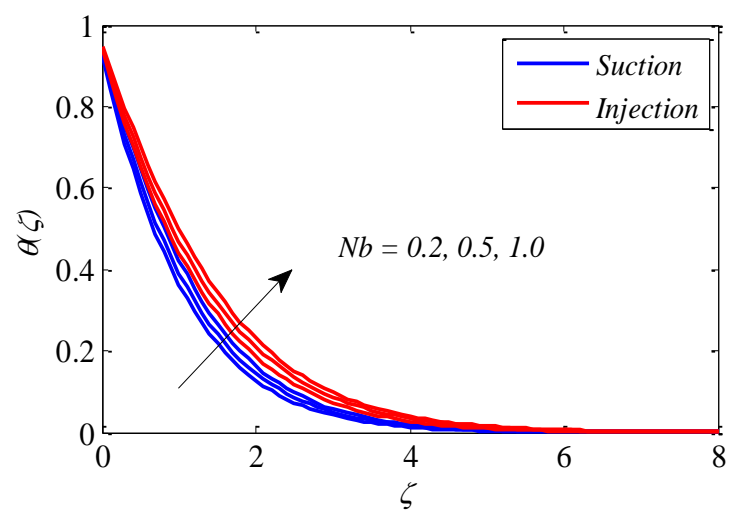

Figure 11. Effect of $N b$ on $\theta(\zeta)$

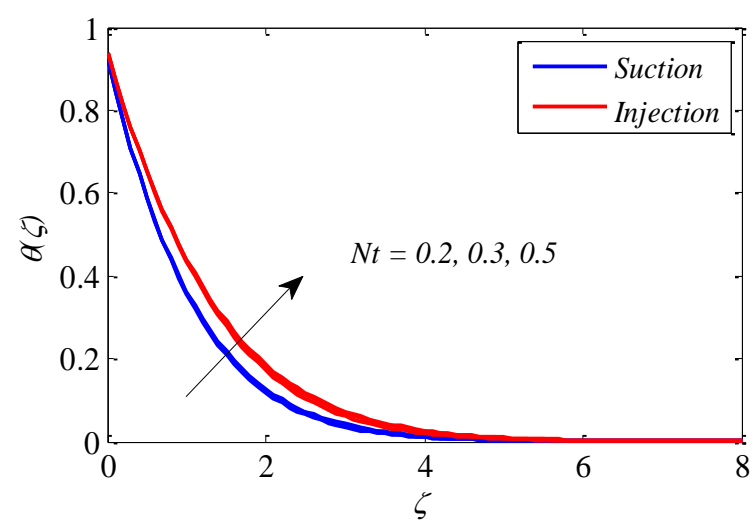

Figure 12. Effect of $N t$ on $\theta(\zeta)$ 


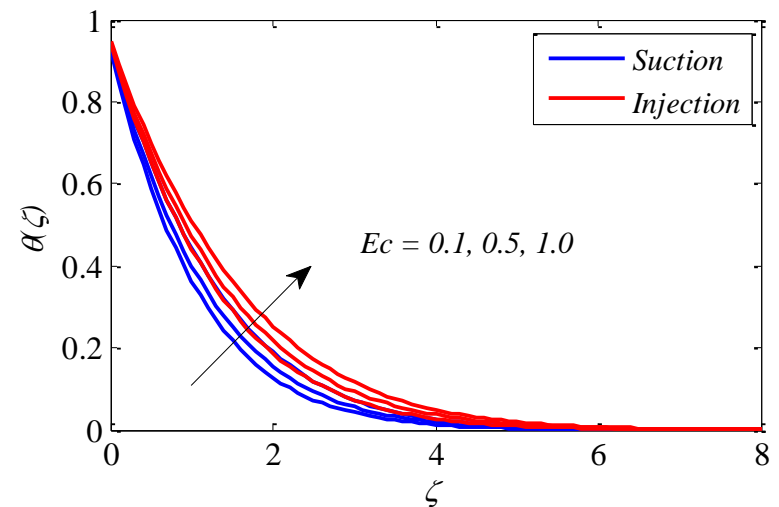

Figure 13. Effect of $E c$ on $\theta(\zeta)$

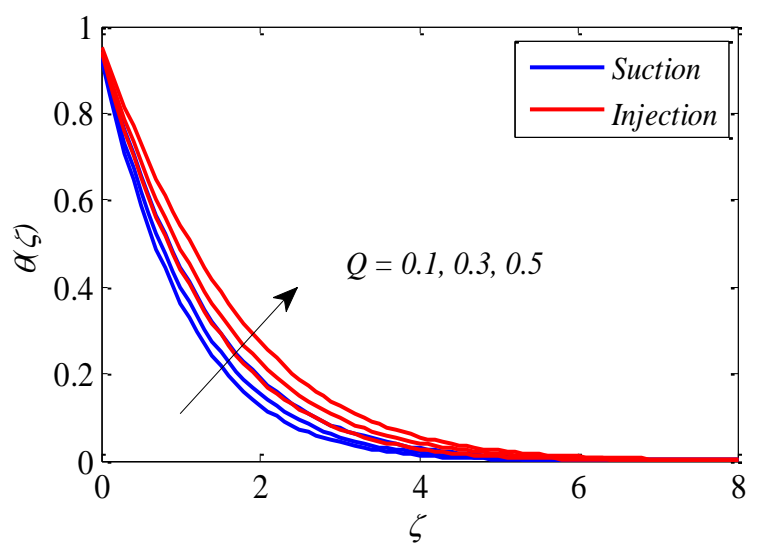

Figure 14. Effect of $Q$ on $\theta(\zeta)$

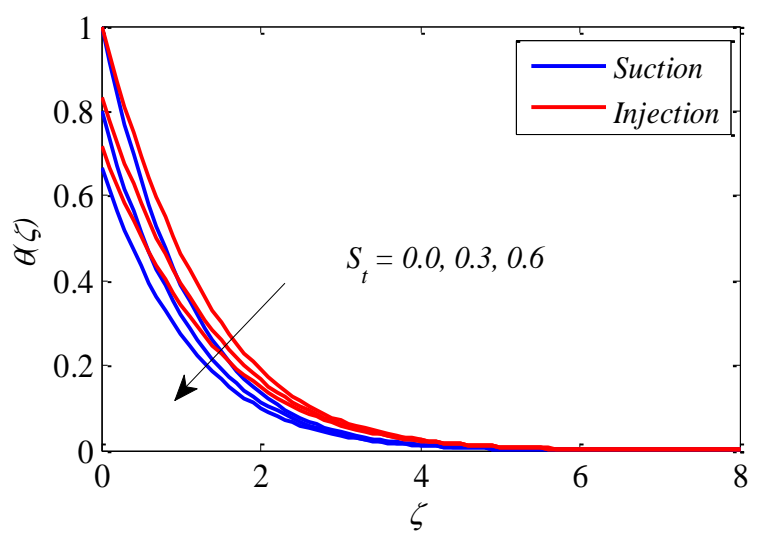

Figure 15. Effect of $S_{t}$ on $\theta(\zeta)$

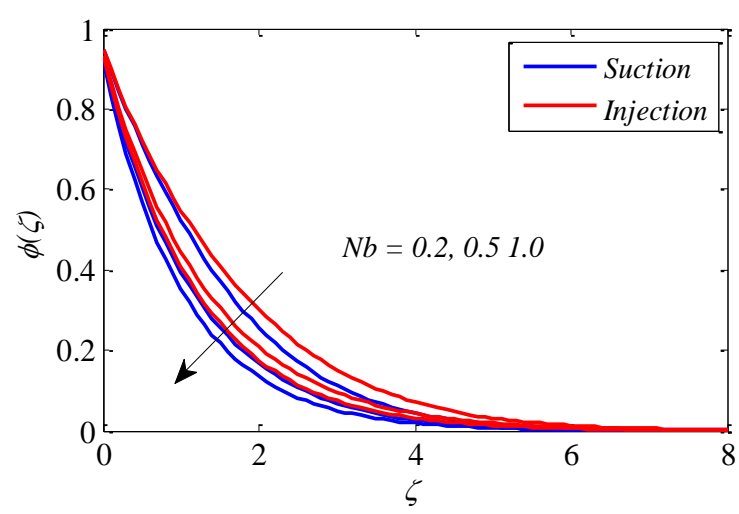

Figure 16. Effect of $N b$ on $\phi(\zeta)$

Figure 14 shows the effect of heat source parameter $Q$ on temperature. The figure declares that the temperature accelerates for various values of $Q$ due to heat generation exist in the thermal boundary layer and hence temperature increases. This acceleration is more for injection case. Figure 15 gives variation of temperature profiles for different values of thermal slip parameter $S_{t}$. From this figure we infer that, the temperature of the boundary layer reduces with an increase in the thermal slip parameter. Concentration profile for various values of Brownian motion parameter $\mathrm{Nb}$ is shown in Figure 16. We noticed that the concentration profile decelerates with an increase in $N b$ for both cases.

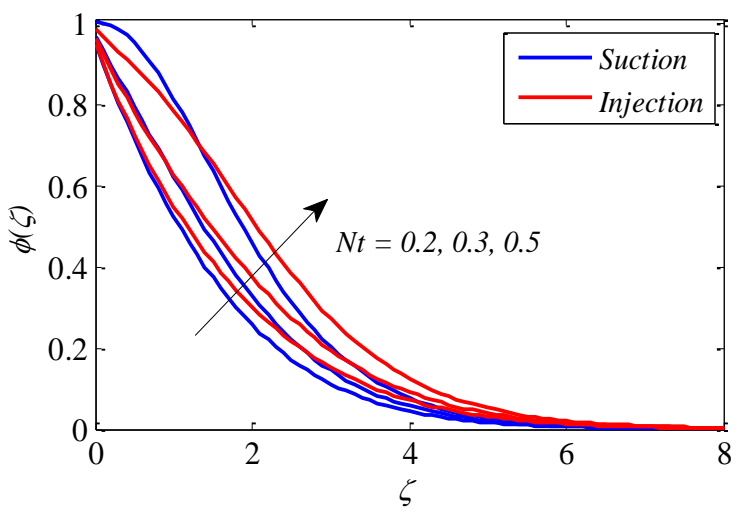

Figure 17. Effect of $N t$ on $\phi(\zeta)$

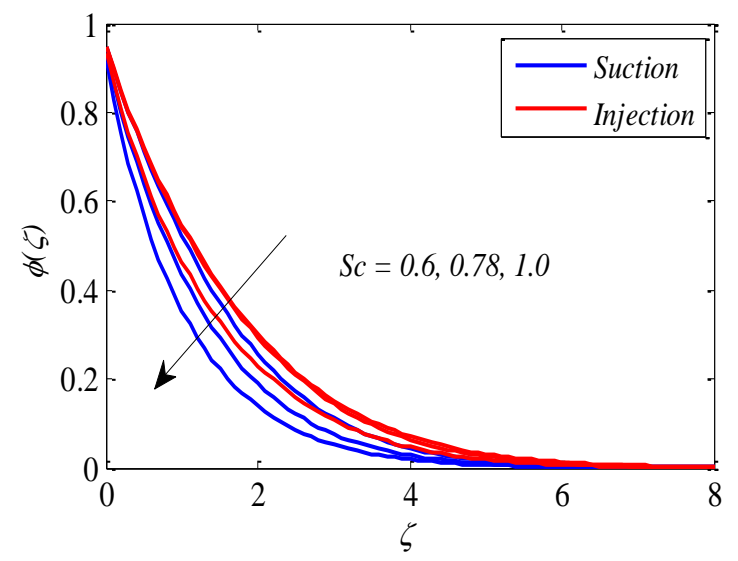

Figure 18. Effect of $S c$ on $\phi(\zeta)$

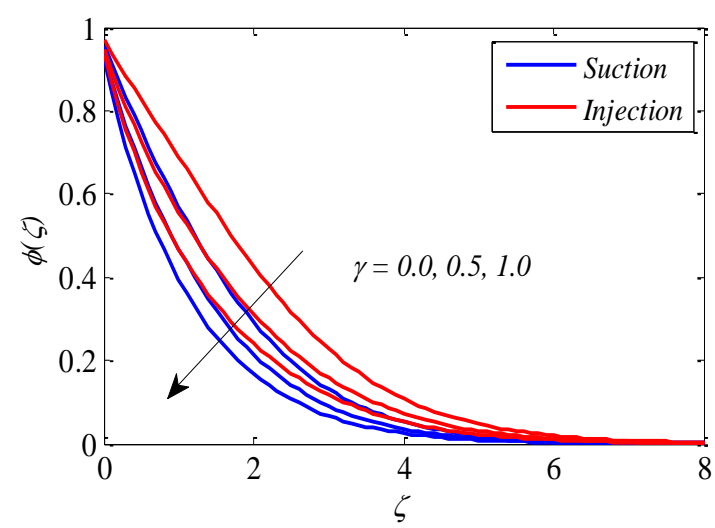

Figure 19. Effect of $\gamma$ on $\phi(\zeta)$

Figure 17 has been plotted to demonstrate the effects of the thermophoresis parameter $N t$ on the dimensionless concentration profile. We noticed that the concentration 
profile increase with an increasing in the value of $N t$ for suction and injection. Effect of Schmidt number $S c$ on concentration distribution is displayed in Figure 18. Here concentration profile decreases when $S c$ increases. Physically the Schmidt number is dependent on mass diffusion $D_{B}$ and an increase in $S c$ corresponds to a decrease in mass diffusion and the concentration. Figure 19 exposes the variation of chemical reaction parameter $\gamma$ on concentration profile. It is shows that concentration profile decreases with increase in the values of $\gamma$. The effect of solutal slip parameter $S_{c}$ on the concentration profiles is plotted in Figure 20. It reveals that the concentration profiles decrease with increase in $S_{c}$.

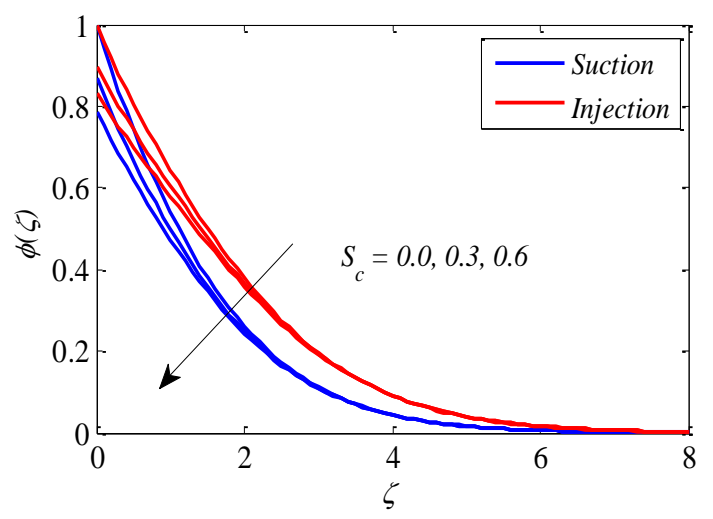

Figure 20. Effect of $S_{c}$ on $\phi(\zeta)$

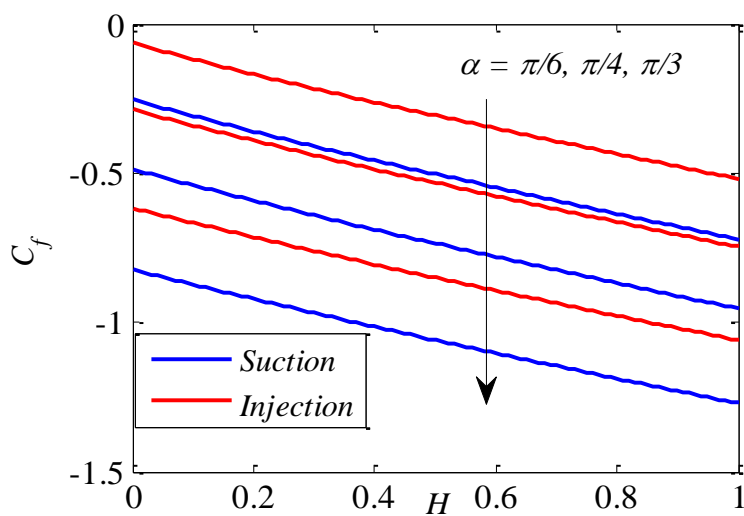

Figure 21. Effect of $H$ and $\alpha$ on skin friction coefficient

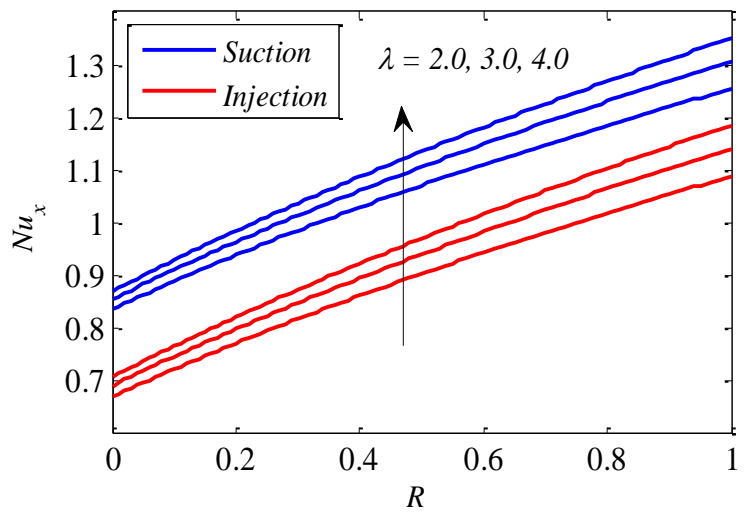

Figure 22. Effect of $R$ and $\lambda$ on local Nusselt number
Figure 21 is initiated to know the impact of magnetic parameter $H$ and inclination parameter $\alpha$ on skin friction coefficient. It is clear that the skin friction declines with both $H$ and $\alpha$. From Figures 22 and 23, we infer that heat transfer rate decreases with viscous dissipation $E c$ and Brownian motion parameter $N b$. It is also noticed that heat transfer rate increases with radiation parameter $R$ and buoyancy parameter $\lambda$ for both the cases. Figure 24 displays the impact of solutal slip parameter $S_{c}$ and Schmidt number $S c$ on mass transfer rate. Local Sherwood number increases with an increase in $S c$ and $S_{c}$. To endorse the veracity of the present analysis, obtained results of $-f^{\prime \prime}(0)$ and $-\theta^{\prime}(0)$ have been compared with the existing solutions in Tables 2 and 3 .

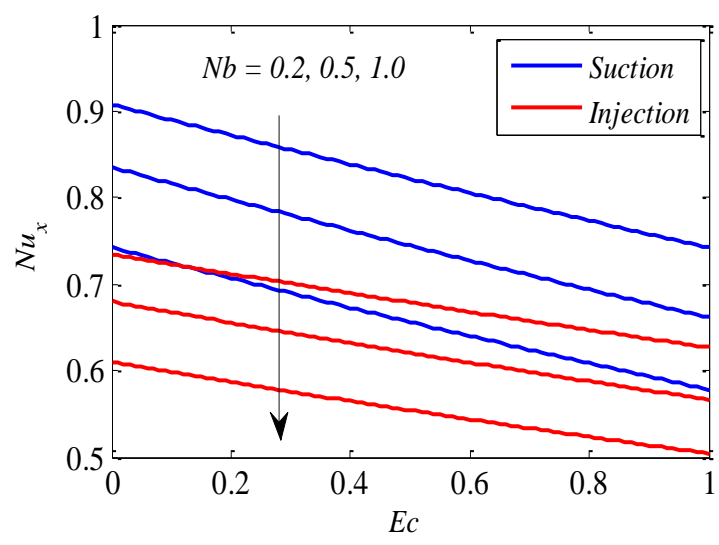

Figure 23. Effect of $E c$ and $N b$ on local Nusselt number

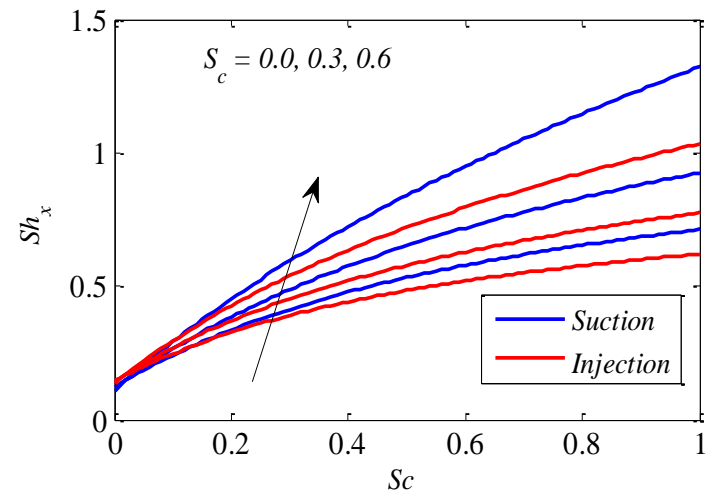

Figure 24. Effect of $S c$ and $S_{c}$ on local Sherwood number

Table 2. Comparison of $-\theta^{\prime}(0)$ for different values of $M, \operatorname{Pr}, E c$ and $R$ when $\beta \rightarrow \infty, \lambda=\delta=H=K=N t=$ $N b=S=S_{v}=S_{t}=S_{c}=0.0, Q=M=0.0$

\begin{tabular}{|c|c|c|c|c|c|}
\hline$E c$ & $R$ & $P r$ & $\begin{array}{c}\text { Ishak } \\
{[29]}\end{array}$ & $\begin{array}{c}\text { Seini and } \\
\text { Makinde } \\
{[30]}\end{array}$ & HAM \\
\hline 0.0 & 0.0 & 1.0 & 0.9547 & 0.954811 & 0.954783 \\
\hline 0.0 & 0.0 & 3.0 & 1.8691 & 1.869069 & 1.869067 \\
\hline 0.0 & 1.0 & 1.0 & 0.5315 & -- & 0.531503 \\
\hline 0.9 & 0.0 & 1.0 & 0.5385 & -- & 0.538541 \\
\hline 0.9 & 0.0 & 3.0 & 0.8301 & -- & 0.830137 \\
\hline 0.9 & 1.0 & 1.0 & 0.3343 & -- & 0.334521 \\
\hline 0.9 & 1.0 & 3.0 & 0.6055 & -- & 0.605519 \\
\hline
\end{tabular}


Table 3. Comparison of $-\theta^{\prime}(0)$ and $\phi^{\prime}(0)$ for different values of $\beta$ when $\lambda=\delta=3.0, H=K=1.0, N t=N b=$ $0.5, S=0.7, R=1.0, \operatorname{Pr}=0.72, S_{v}=0.1, S_{t}=0.3, S_{c}=$ $0.7, \gamma=1.0, \alpha=\pi / 4, E c=Q=0.0$

\begin{tabular}{|c|c|c|c|c|}
\hline & \multicolumn{2}{|c|}{ Eswara Rao [31] } & \multicolumn{2}{c|}{ HAM } \\
\hline$\beta$ & $-\theta^{\prime}(0)$ & $-\phi^{\prime}(0)$ & $-\theta^{\prime}(0)$ & $-\phi^{\prime}(0)$ \\
\hline 0.3 & 0.523109 & 0.589403 & 0.523113 & 0.589411 \\
\hline 0.6 & 0.512534 & 0.588060 & 0.512534 & 0.588060 \\
\hline
\end{tabular}

\section{CONCLUSIONS}

In this paper, we obtained the numerical analysis of magneto-hydrodynamic Casson nanofluid flow at an exponentially inclined stretching plate, considering thermal radiation, heat source, viscous dissipation and chemical reaction. The main findings of computational results are summarized below:

- Velocity is an increasing function of the parameters $\lambda$ and $\delta$.

- Temperature profile falls down against Prandtl number and thermal slip parameter, while Brownian motion parameter, thermophoresis number and radiation parameter enhances it.

- Concentration profile reduces against Brownian motion parameter and Schmidt number while it enhances for thermophoresis number.

- Local Nusselt number enhances for buoyancy parameter.

- $\quad$ By increasing solutal slip parameter local Sherwood number enhances.

\section{REFERENCES}

[1] Gupta, P.S., Gupta, A.S. (1977). Heat and mass transfer on a stretching sheet with suction or blowing. Canadian Journal of Chemical Engineering, 55(6): 744-746. https://doi.org/10.1002/cjce.5450550619

[2] Cortell, R. (2007). Viscous flow and heat transfer over a nonlinearly stretching sheet. Applied Mathematics and Computation, $184(2)$ : 864-873. https://doi.org/10.1016/j.amc.2006.06.077

[3] Shahzad, A., Ali, R., Khan, M. (2012). On the exact solution for axisymmetric flow and heat transfer over a non radially stretching sheet. Chinese Physics Letter, 29(8): $\quad 084705 . \quad$ https://doi.org/10.1088/0256307X/29/8/084705

[4] Tiwari, R.K., Das, M.K. (2007). Heat transfer augmentation in two sided lid driven differentially heated square cavity utilizing nanofluids. International Journal of Heat and Mass Transfer, 50(9-10): 2002-2018. http://doi.org/10.1016/j.ijheatmasstransfer.2006.09.034

[5] Abba, Z., Hayat, T. (2011). Stagnation slip flow and heat transfer over a nonlinear stretching sheet. Numerical Methods for Partial Differential Equations, 27(2): 302314. https://doi.org/10.1002/num.20523

[6] Hayat, T., Qasim, M., Mesloub, S. (2011). MHD flow and heat transfer over permeable stretching sheet with slip conditions. Numerical Methods in Fluids, 66(8): 963-975. https://doi.org/10.1002/fld.2294
[7] Cortell, R. (2014). Fluid flow and radiative nonlinear heat transfer over a stretching sheet. Journal of King Saud University-Science, 26(2): 161-167. https://doi.org/10.1016/j.jksus.2013.08.004

[8] Choi, S.U.S., Eastman, J.A. (1995). Enhancing thermal conductivity of fluids with nanoparticles. ASME International Mechanical Engineering Congress Exposition SanFrancisco, USA, ASME, FED231/MD66, pp. 99-105.

[9] Makinde, O.D., Aziz, A. (2011). Boundary layer flow of a nanofluid past a stretching sheet with a convective boundary condition. International Journal of Thermal Science, 50(7): $1326-1332$. https://doi.org/10.1016/j.ijthermalsci.2011.02.019

[10] Mansur, S., Ishak, A. (2013). The flow and heat transfer of a nanofluid past a stretching/shrinking sheet with a convective boundary condition. Abstract and Applied Analysis, $\quad 2013(2)$ : 350647. https://doi.org/10.1155/2013/350647

[11] Mabood, F., Khan, W.A., Ismail, A.I.M. (2015). MHD boundary layer flow and heat transfer of nanofluids over a nonlinear stretching sheet: A numerical study. Journal of Magnetism and Magnetic Materials, 374: 569-576. https://doi.org/10.1016/j.immm.2014.09.013

[12] Hady, F.M., Ibrahim, F.S., Abdel-Gaied, S.M., Eid, M.R. (2012). Radiation effect on viscous flow of a nanofluid and heat transfer over a nonlinearly stretching sheet. Nanoscale Research Letter, 7: 229. https://doi.org/10.1186/1556-276X-7-229

[13] Nadeem, S., Ul Haq, R., Khan, Z.H. (2014). Numerical solution of non-Newtonian nanofluid over a stretching sheet. Applied Nanoscience, 4(5): 625-631. https://doi.org/10.1007/s13204-013-0235-8

[14] Mustafa, M., Hayat, T., Pop, I., Asghar, S., Obaidat, S. (2011). Stagnation-point flow of a nanofluid towards a stretching sheet. International Journal of Heat and Mass Transfer, 54(25-26): 5588-5594. https://doi.org/10.1016/j.ijheatmasstransfer.2011.07.021

[15] Hamad, M.A.A., Ferdows, M. (2012). Similarity solutions to viscous flow and heat transfer of nanofluid over nonlinearly stretching sheet. Applied Mathematics and $\quad$ Mechanics, 33(7): 923-930. https://doi.org/10.1007/s10483-012-1595-7

[16] Jayarami Reddy, K., Madhusudhan, N.P., Ramakrishna, K. (2018). MHD mixed convection flow of radiating and chemically reactive Casson nanofluid over a nonlinear permeable stretching sheet with viscous dissipation and heat source. Multidiscipline Modelling in Materials and Structures, $14(3)$ : 609-630. https://doi.org/10.1108/MMMS-10-2017-0127

[17] Jayarami Reddy, K., Madhusudhan, N.P., Ramakrishna, K., Abhishek. D. (2018). Numerical investigation of chemical reaction and heat source on radiating MHD stagnation point flow of carreau nanofluid with suction/injection. Defect and Diffusion Forum, 388: 171189.

https://doi.org/10.4028/www.scientific.net.DDF.388.17 1

[18] Suneetha, K., Ibrahim, S.M., Jayarami Reddy, K. (2015). Effects of radiation, viscous and joules dissipation on MHD mixed convective flow in porous medium in Presence of heat source, chemical reaction and Soret. International Journal of Scientific and Innovative Mathematical Research (IJSIMR), 3(2): 769-779. 
[19] Mustafa, M., Khan, J.A. (2015). Model for flow of Casson nanofluid past a non-linearly stretching sheet considering magnetic effects.AIP Advances, 5: 077148. https://doi.org/10.1063/1.4927449

[20] Ibrahim, W., Makinde, O.D. (2016). Magnetohydrodynamic stagnation point flow and heat transfer of Casson nanofluid past a stretching sheet with slip and convective boundary conditions. Journal of Aerospace Engineering, 29(2): 04015037. https://doi.org/10.1061/(ASCE)AS.1943-5525.0000529

[21] Ibrahim, S.M., Kumar, P.V., Lorenzini, G., Mabood. F.(2017). Numerical study of the onset of chemical reaction and heat source on dissipative MHD stagnation point flow of Casson nanofluid over a nonlinear stretching sheet with velocity slip and convective boundary conditions. Journal of Engineering Therophysics, 26(2): 256-271. https://doi.org/11.1134/S18102328170200096

[22] Ibrahim, S.M., Lorenzini, G., Vijaya Kumar, P., Raju, C.S.K. (2017). Influence of chemical reaction and heat source on dissipative MHD mixed convection flow of a Casson nanofluid over a nonlinear permeable stretching sheet. International Journal of Heat and Mass Transfer, 111: 346-355 https://doi.org/10.1016/j.ijheatmasstransfer.2017.03.097

[23] Mondal, M., Biswas, R., Shanchia, K., Hassan, M., Ahmad, S.F. (2018). Numerical investigation with stability convergence analysis of chemically hydromagnetic Casson nanofluid flow in the effects of thermophoresis and brownian motion. International Journal of Heat and Technology, 37(1): 59-70. https://doi.org/10.18280/ijht.370107

[24] Kumar, P.V., Ibrahim, S.M., Lorenzini, G. (2018). The study of three dimensional radiative MHD Casson nanofluid over an exponentially porous stretching sheet with heat source under convective boundary conditions. International Journal of Heat and Technology, 36(1): 110. https://doi.org/10.18280/ijht.360101

[25] Kumar, P.V., Ibrahim, S.M., Lorenzini, G. (2018). Impact of thermal radiation and Joule heating on MHD mixed convection flow of a Jeffrey fluid over a stretching sheet using homotopy analysis method. International Journal of Heat and Technology, 35(4): 978-986. https://doi.org/10.18280/ijht.350434

[26] Hayat, T., Shehzad, S.A., Alsaedi, A. (2012). Soret and Dufour effects on Magnetohydrodynamic (MHD) flow of Casson fluid. Applied Mathematics and Mechanics, 33(10): 1301-1312. https://doi.org/10.1007/s10483-0121623-6

[27] Liao, S.J. (2012). Homotopy Analysis Method in Nonlinear Differential Equations. Springer \& Higher Education Press, Heidelberg.

[28] Nadeem, S., Zaheer, S., Fang, T. (2011). Effects of thermal radiation on the boundary layer flow of a Jeffrey fluid over an exponentially stretching surface. Numerical Algorithms, 57(2):

187-205. https://doi.org/10.1007/s11075-010-9423-8

[29] Ishak, A. (2011). MHD boundary layer flow due to an exponentially stretching sheet with radiation effect. Sains Malaysian, 40(4): 391-395.

[30] Seini, Y.I., Makinde, O.D. (2013). MHD boundary layer flow due to exponential stretching surface with radiation and chemical reaction. Mathematical Problems in

Engineering,

2013:

163614.

https://dx.doi.org/10/1155/2013/163614

[31] Eswara Rao, E. (2018). The effects of thermal radiation and chemical reaction on MHD flow of a Casson fluid over an exponentially inclined stretching surface. Journal of Physics: Conference Series, 012158. https://doi.org/10.1088/1742-6596/1000/1/012158

\section{NOMENCLATURE}

B

$B_{0}$

C

$C_{0}$

$C_{f}$

$C_{w}$

$C_{\infty}$

$D_{B}$

$D_{T}$

Ec

Gr

Gc

H

$J_{w}$

$K^{*}$

K

L

$M^{*}$

M

$N^{*}$

$N$

$\mathrm{Nb}$

$N t$

$N u_{x}$

$P^{*}$

$P$

$P_{y}$

$P r$

$Q_{0}$

$Q$

$R$

$R e_{x}$

$q_{r}$

$q_{w}$

$S$

$S_{v}$

$S_{t}$

$S_{c}$

$S c$

$S h_{x}$

$T$

$T_{0}$

$T_{w}$

$T_{\infty}$ variable magnetic field strength, $\mathrm{N} . \mathrm{m}^{-1} \cdot \mathrm{A}^{-1}$

constant

nanoparticle concentration, $\mathrm{kg} \cdot \mathrm{m}^{-3}$

reference concentration

skin friction coefficientlocal

nanoparticle concentration at the surface of the sheet ambient nanoparticle concentration

Brownian diffusion coefficient, $\mathrm{m}^{2}$. $\mathrm{s}^{-1}$

thermophoretic diffusion coefficient, $\mathrm{m}^{2} . \mathrm{s}^{-1}$

viscous dissipation parameter, W. $\mathrm{m}^{-2}$

local grashof number

local solutal grashof number

Hartman number

mass flux

permeable parameter

non-dimensional porous parameter

reference length

constant

thermal slip parameter

constant

velocity slip parameters

Brownian motion parameter

thermophoresis parameter

local Nusselt number

constant

solutal slip parameter

yield stress, $\mathrm{Nm}^{-2}$

Prandtl number

heat source coefficient

heat source parameter

radiation parameter

local Reynolds number

radiative heat flux, $\mathrm{W} . \mathrm{m}^{-1}$

surface heat flux

suction/injection parameter

non dimensional velocity slip parameter

non dimensional thermal slip parameter

non dimensional solutal slip parameter

Schmidt number

Sherwood number

Temperature, $\mathrm{K}$

reference temperature, $\mathrm{K}$

surface temperature, $\mathrm{K}$

ambient fluid temperature, $\mathrm{K}$ 
Stretching velocity, $\mathrm{m} . \mathrm{s}^{-1}$

$U_{0} \quad$ reference velocity, $\mathrm{m} . \mathrm{s}^{-1}$

$u, v \quad$ velocity components in $x, y$, directions, $\mathrm{m} . \mathrm{s}^{-1}$

\section{Greek symbols}

$v \quad$ kinematic viscosity, $\mathrm{m}^{2} . \mathrm{s}^{-1}$

$\sigma \quad$ electrical conductivity of the fluid, $S . \mathrm{m}^{-1}$

$\rho \quad$ fluid density, $\mathrm{kg} . \mathrm{m}^{-3}$

$\alpha \quad$ inclination angle

$\tau_{w} \quad$ surface shear rate, $\mathrm{Pa}$

$\beta \quad$ Casson fluid parameter

$h_{f} \quad$ convective heat transfer

coefficient of the fluid

$k \quad$ thermal conductivity of the fluid, W. $\mathrm{m}^{-1} \cdot \mathrm{k}^{-1}$

$\sigma^{*} \quad$ Stefan-Boltzman constant, W. $\mathrm{m}^{-2} \cdot \mathrm{K}^{-4}$

$c_{p} \quad$ specific at constant pressure, $\mathrm{J}_{\mathrm{K}} \mathrm{K}^{-1} \cdot \mathrm{kg}^{-1}$

$p \quad$ fluid pressure, $\mathrm{Pa}$

\section{Subscript}

$\mathbf{S}$

$w$

$\infty$ plastic dynamic viscosity of the fluid, Pa. $\mathrm{s}$ acceleration due to gravity, $\mathrm{m} . \mathrm{s}^{-2}$ velocity profiles, $\mathrm{m}$. $\mathrm{s}^{-1}$

temperature profile concentration profile mean absorption coefficient, $\mathrm{m}^{-1}$ similarity variable chemical reaction rate buoyancy parameter solutal buoyancy parameter chemical reaction parameter coefficient of thermal expansion coefficient of solutal expansion

conditions at the wall ambient condition 